\title{
Energy efficient technologies of microclimate creation in animal husbandry
}

\author{
Andreev Leonid \\ Mechanics and technology Institute \\ Federal state budgetary educational institution of higher \\ education "State agrarian University of Northern Zauralye" \\ Tyumen, Russia \\ andreev@tmn-tlt.ru
}

\author{
Yurkin Vladimir \\ Mechanics and technology Institute \\ Federal state budgetary educational institution of higher \\ education "State agrarian University of Northern Zauralye" \\ Tyumen, Russia
}

\begin{abstract}
A number of issues arose due to the transfer of animal husbandry to the industrial basis. They are associated with high stocking density of animals in a limited space. They are primarily the high energy consumption for creation of optimal microclimate, the increase in the risk of spreading infections transmitted by aerogenic microbes, the increase of environmental load on the environment and the deterioration of working conditions of the staff. These problems are mainly associated with the use of ineffective methods of ventilating livestock buildings. In this paper, the authors propose using a system of partial recirculation of ventilation air with its simultaneous highperformance cleaning and disinfection in livestock complexes. As the filter element, it is proposed to use a wet single-zone electrostatic precipitator having high efficiency to clean the air from dust, germs and harmful gases such as ammonia and hydrogen sulfide. To improve the efficiency of purification and decontamination of the air environment of livestock buildings, it is advisable to use two-stage wet electrostatic precipitators with increased efficiency of disinfection of air environment and high performance in air cleaning from dust and harmful gases.
\end{abstract}

Keywords - electrostatic precipitator; animal husbandry; dust; microorganisms; ammonia; hydrogen sulfide.

Analysis of the animal husbandry development shows that there is a path of industrialization, concentration and specialization of this industry. This process is irreversible because it develops in the directions of the improvement of technological processes, types of buildings for animals, improvement of quality and nutritional value of fodder, improvement of general culture of animal husbandry.

A number of government decrees on the transfer of animal husbandry and poultry breeding to the industrial basis were adopted in Russia in the last century. As a result, large industrial livestock farms began to appear in different parts of Russia, protecting the country's food security.

Industrial methods of livestock are characterized by high concentration and density of animals. With high concentration of livestock per unit area, the state and composition of the air deteriorate, because when an animal lives in an enclosed space, the air becomes polluted with ammonia, hydrogen sulfide, carbon dioxide, organic compounds and dust. The result is increased mortality, reduced weight gain and safety of animals, the risk of the spread of aerogenic infections increases. The results of numerous studies indicate that farms with animals in rooms with air, polluted with ammonia, hydrogen sulfide, carbon dioxide, incur significant losses from reduced productivity of animals, an increasing mortality rate (especially piglets after birth and weaning), and feed wastage per unit of production. In addition, animals have a reduced natural immunological resistance to disease in conditions of poor climate. Studies, carried out on young pigs, have shown that good indoor climate has a positive effect on metabolic processes in the animal organism and helps to increase the liveweight gain with the same amount of feed [1].

The concentration of the above-mentioned harmful active components of the air environment to the maximum permissible values decreases with the supply and exhaust of forced ventilation, the urgency of the development, implementation and use of which in animal production units is . In its turn, gases, dust and microorganisms emitted through the ventilation system into the environment are distributed horizontally with the exhaust air at a fairly large distance which depends on the power of the exhaust ventilation, spaceplanning decisions, weather conditions, etc. In Fig. 1 shows the data on the concentration of micro-organisms, specific odor and ammonia in the air, depending at the distance from large livestock complexes [2].

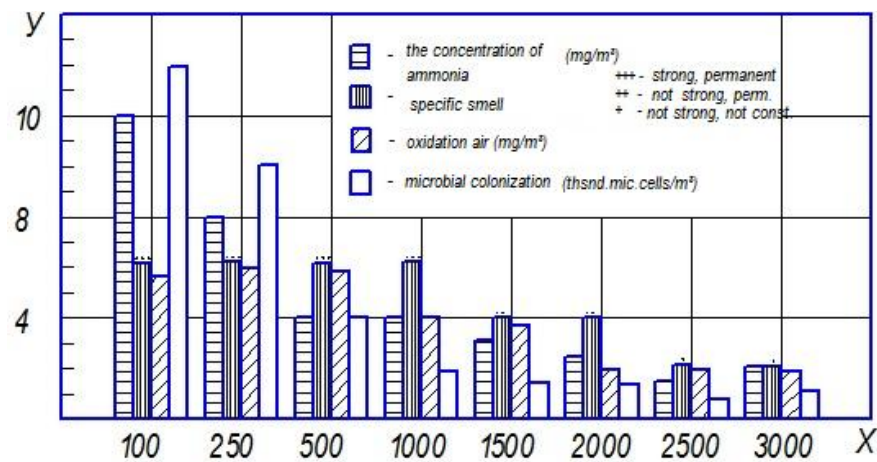

Fig. 1. The concentration of harmful impurities in the atmospheric air depending at the distance from the complex, where $\mathrm{Y}$ - the concentration of contaminants in the atmospheric air; $\mathrm{X}$ - the distance from the complex. 
These examples show how broad the migration of microflora and infiltration of ventilation air is in the existing cattle-breeding complexes, which creates a constant threat of introduction of infectious diseases and their spread among the buildings of the complex and as a rule leads to increased risk of introduction and spread of infectious diseases transmitted by aerogenic way.

It is necessary to consider that the livestock industry is very energy intensive: for example, the cost structure of pork energy costs increased by $10-15 \%$. In its turn, the main part of energy (about 50\%) is used to maintain the necessary microclimate [3].

In the transitional and cold periods of the year, the air pumped into the pig farm should be heated. For these purposes, around 60-80\% of all thermal energy spent on the livestock complexes is consumed. At the same time, a significant amount of heat is released from the premises into the atmosphere in addition to pollutants from the ventilation air. Considering that the heating season in most parts of Russia lasts from six to nine months, the importance of the problem of heat loss becomes apparent.

Thus, in the conditions of intensive development of animal industry, an important engineering challenge is the creation of ventilation and heating systems (VHS), which would provide the necessary hygienic conditions for the animals, combined with the complex scientific and practical activities that reduce energy consumption for creation of a microclimate.

Thus, modern industrial farming has faced a number of serious problems, without solution for which it is impossible to further the successful development of these industries.

This is primarily:

- energy and resource saving;

- protection of systems from penetration and spread of infectious diseases in an aerogenic way;

- protection of the environment from pollution in the area of livestock breeding complexes;

- the social aspect (the creation of more favourable working conditions for staff) [4].

In domestic and foreign literature, since the seventies, there were publications related to protection of the air environment in livestock buildings from various harmful active ingredients. The bulk of these publications is devoted to the study of the air environment of livestock buildings concerning the presence of dust, microorganisms, harmful gases and odors, and the impact of these parameters on animal performance and health. The other part of the publications is devoted to the methods of study of the air environment, technical and economic issues. The number of works devoted to the research of methods and means of air purification from microbial and bacteriological pollution, harmful gases and odors is very limited.

One way of utilizing the heat of the livestock facilities is recirculated air. However, in this case, there is an accumulation of dust, moisture, germs and harmful gases in the air environment of the room. Thus, it is necessary to use a scheme of partial recirculation of the air with its highly effective disinfection and purification against the abovementioned components. Moreover, the partial scheme implies a continuous removal of some volume of internal air to remove excess carbon dioxide and moisture and simultaneous mixing of fresh, filtered air recirculation for the enrichment of the latter with oxygen (Fig. 2).

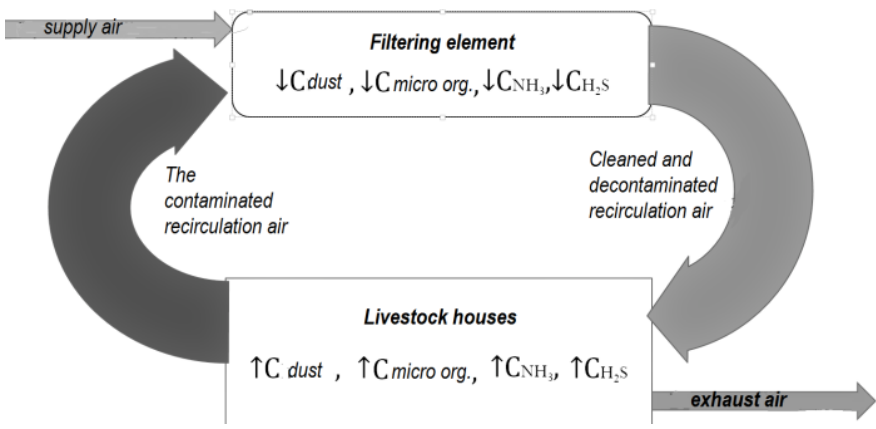

Fig. 2. Scheme of partial recirculation of ventilating air in livestock house

Air filters are used to clean ventilation air, including recirculating air. Modern manufacturing offers a wide range of air filters and filter elements that have different technological and design parameters, the comparison of which shows the obvious advantage of electrostatic precipitators. The action of the electrostatic precipitator is based on corona discharge, in the field of which the particles, suspended in the air being purified, are charged and they are deposited on the collecting electrodes under the action of electric forces.

Corona discharge is a form of incomplete electrical discharge characteristic of the electrodes systems with a strongly nonuniform field. Ionization processes in corona discharge are concentrated in a narrow region where the field strength is the greatest. This area is called a "cover" of the crown. In the outer region of corona discharge, ionization processes are absent as the field strength, ionization are insufficient. In this region, there are negative or positive poles, depending on the polarity of the corona ions, which create in the interelectrode space of a unipolar space charge. If in the outer region of the corona discharge, which occupies the greater part of the interelectrode space, there are solid or liquid particles, then the ions from the space, deposited on the surface of these particles, are receiving charge and give excessive electric charge, i.e. is charging by particles. Furthermore, under the action of an electric field, charged particles move in the direction perpendicular to the flow and they are deposited on the precipitation electrodes.

In the process of ionization of air by corona discharge, inside the "case" of the crown, there is a violation of intramolecular bonds in the gas constituents of air (oxygen, nitrogen, etc.) with the further formation of ozone, nitrogen oxides, etc. thus, the air is illuminated to the eyes in the electrostatic precipitator, saturated with ozone, nitrogen oxides etc. 


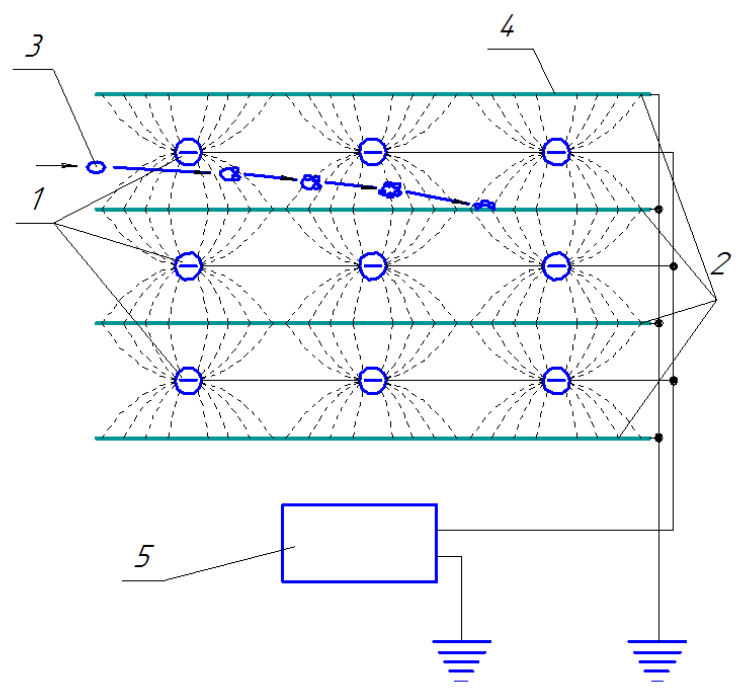

Fig. 3. Electrostatic precipitator. 1 - discharge electrodes; 2 -grounded precipitation electrodes; 3 - deposited particle; 4 - potential of flat electrodes in the charging zone; 5 - high voltage source

Electrostatic precipitators have several advantages, such as:

- low aerodynamic resistance;

- a high degree of purification from dust particles of the size from 10 to 0.01 micrometers or less;

- the possibility of regeneration of the filter element;

- the possibility of automation of the cleaning process;

- low own consumption of electricity;

- low cost of purification.

It is also impossible to exclude the possibility of direct bactericidal (isoelectric effect) and bacteriostatic effects of strong electrostatic fields on microorganisms. It should be noted that the atomic oxygen formed by ionization of air and ozone is a powerful oxidant. The impact of these agents on the molecules of organic substances, which are the carriers of the smell in the air, creates the effect of deodorization. The part of the result is that the air is cleaned in electrostatic precipitators and has a nice freshness [5].

In its turn, the recirculating precipitators, according to the requirements for cleaning recirculating air, must have a high dust retention capacity and ability for continuous regeneration of the collecting electrodes, deposited on them from the dust particles. These are the qualities of a wet single-zone electrostatic precipitator (Fig. 4) specially developed in cooperation with Chelyabinsk State Agroengineering Academy and State Agrarian University of Northern TransUral.

The wet single-zone electrostatic precipitator consists of two main parts: the upper part of the corona electrodes and a system of high-voltage insulators; the lower part with a liquid container and the drain valve for removing contaminated washing fluid.
Needle or wire electrodes are used as corona electrodes. Precipitation electrodes are made in the form of parallel flat discs that rotate on a shaft of an electrostatic precipitator.

Precipitation electrodes are rotating at a certain speed on the shaft of an electrostatic precipitator and they are constantly wetted with liquid on the bottom of the precipitator. Deposition of aerosol particles from an air stream occurs in the upper part of the electrostatic precipitator on the surface of the precipitation electrodes, coated with a thin layer of the liquid.

The design of electrostatic precipitator allows one to continuously clean the collecting electrodes of the settled aerosols and to purify the filtered air from the harmful gas components due to ozone and the liquid around the collecting electrodes.

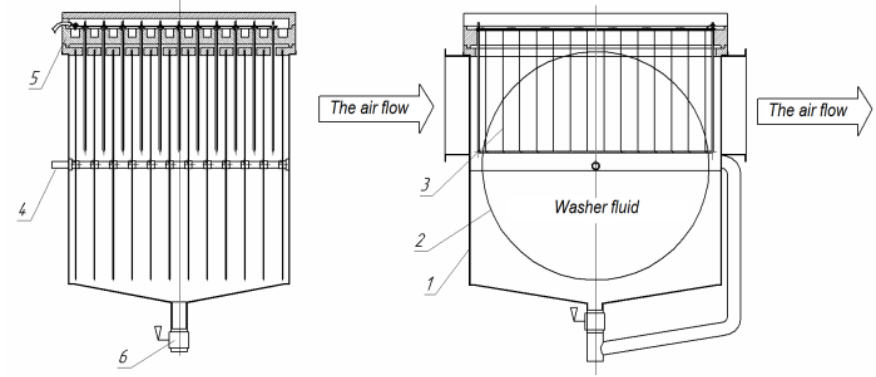

a)
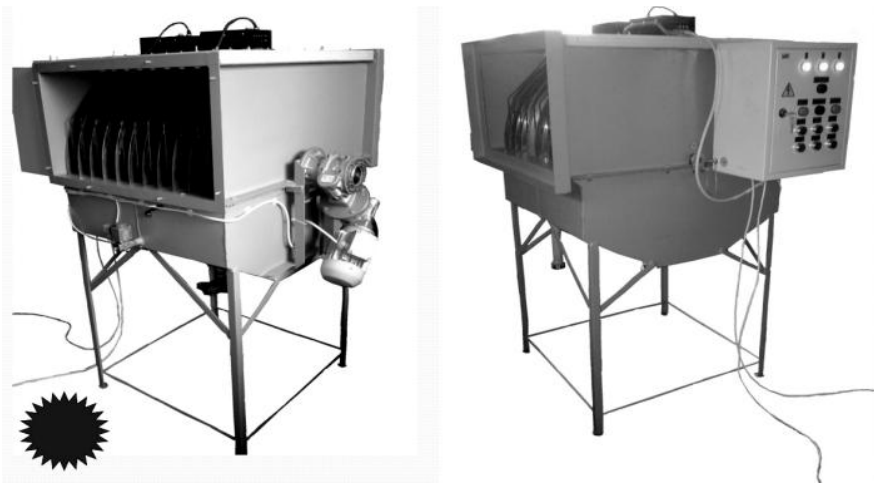

b)

Fig. 4. Wet single-zone electrostatic precipitator

$$
\text { a) device; b) appearance }
$$

1 - shell; 2 - collecting electrode; 3 - discharge electrodes; 4 shaft of an electrostatic precipitator; 5 - insulating plate; 6 -drain valve

The efficiency of air cleaning from dust by the electrostatic precipitator and by a wet electrostatic precipitator is determined by the formula of Deutsch:

$$
\eta=1-e^{\left(-\frac{w l}{h u}\right)}
$$

where $\mathrm{w}$ - the drift velocity of particles, $\mathrm{m} / \mathrm{s} ; 1$ - length of the active part of the electrostatic precipitator, $\mathrm{m} ; \mathrm{h}$ - the interelectrode distance, $\mathrm{m}$; $\mathrm{u}$ - air velocity, $\mathrm{m} / \mathrm{s}$.

In the requirements for purification systems of recirculation air, it is stated that cleaning should be done for 1- 
micrometer sized dust particles or larger, for which the drift velocity is calculated according to the formula:

$$
w=0.11810^{-10}\left(E^{2} d_{\text {part }} / 2 \mu\right)
$$

where $E$ - field strength of a corona discharge, $v / m ; d_{\text {part }}$ size of the entrained particles, micrometer; $\mu-$ dynamic viscosity of air, PA•s.

If one considers that the dynamic viscosity of air is $18 \cdot 10^{-6}$ $\mathrm{PA} \bullet \mathrm{s}$, and the field strength of the corona discharge with the wet electrostatic precipitator is $6.8 \mathrm{kV} / \mathrm{cm}$, the drift velocity of the 1 -micrometer particles or more will be above $0.15 \mathrm{~m} / \mathrm{s}$.

The active length of collecting electrodes 1 of the wet electrostatic precipitator is given by:

$$
l=\frac{\frac{1}{2} \sqrt{2 R b-b^{2}} \cdot \sqrt{R^{2}-\frac{2 R b-b^{2}}{4}}+2 \pi R^{2} \frac{90-\arccos \frac{R-b}{R}}{360}}{R-b}
$$

where $\mathrm{R}$ - the radius of the collecting electrode, $\mathrm{m} ; \mathrm{b}$ depth of fixation of the receiving electrode in the upper insulating plate, $\mathrm{m}$.

Knowing the efficiency of the wet electrostatic precipitator for cleaning the air from dust, it is possible to calculate the removal efficiency of microorganisms. For this, let us use the known expression:

$$
\eta_{\text {micro }}=1-\left(1-\eta_{\text {dust }}\right)^{0,66}
$$

To determine the efficiency of the wet electrostatic precipitator for cleaning of the $\mathrm{i}$-th gas, let us use the equation:

$$
\eta_{i}=1-\exp \left[-\frac{\left(k_{i}+k_{\mathrm{H}_{2} \mathrm{O}}\right) \cdot l}{u}\right]
$$

where $k_{i}$ - ratio of oxidation rate of $i$-th gas with ozone; $\mathrm{k}_{\mathrm{H} 2 \mathrm{O}}$ is the rate of absorption of the $\mathrm{i}$-th gas with water.

The rate coefficients of the oxidation and absorption are tabulated values for each gas. In the absence of the factor in the table, it is determined experimentally.

Comprehensive laboratory and production testing of the wet single-zone electrostatic precipitator showed its high efficiency for cleaning the air from dust particles, microorganisms, and harmful gases such as ammonia and sulfides (Fig. 5).

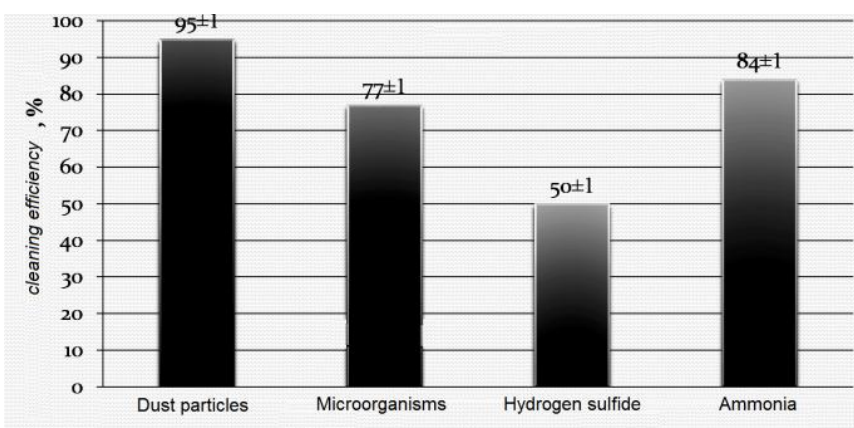

Fig. 5. Efficiency of wet single-zone electrostatic precipitator
Fig. 5 shows that cleaning efficiency of the recirculation air for the wet single-zone electrostatic reaches: for dust particles $-95 \%$, for microorganisms $-77 \%$, for hydrogen sulfide $-50 \%$ and for ammonia $-84 \%$.

Production tests of this installation were carried out on several large pig farms in Chelyabinsk and Tyumen regions. In particular, Krasnogorsk pig farm, pig farm "Kashtak" (Chelyabinsk region) and pig farm "Consent" (Tyumen region) took part in it.

In the Krasnogorsk pig farm, tests were carried out on the land for growing of piglets weaned. Two sectors with identical production and climatic parameters were selected: experimental and control. In the experimental sector, the established system of cleaning of the recirculating air was based on the wet single-zone electrostatic precipitator.

TABLE I. Key performance indicators

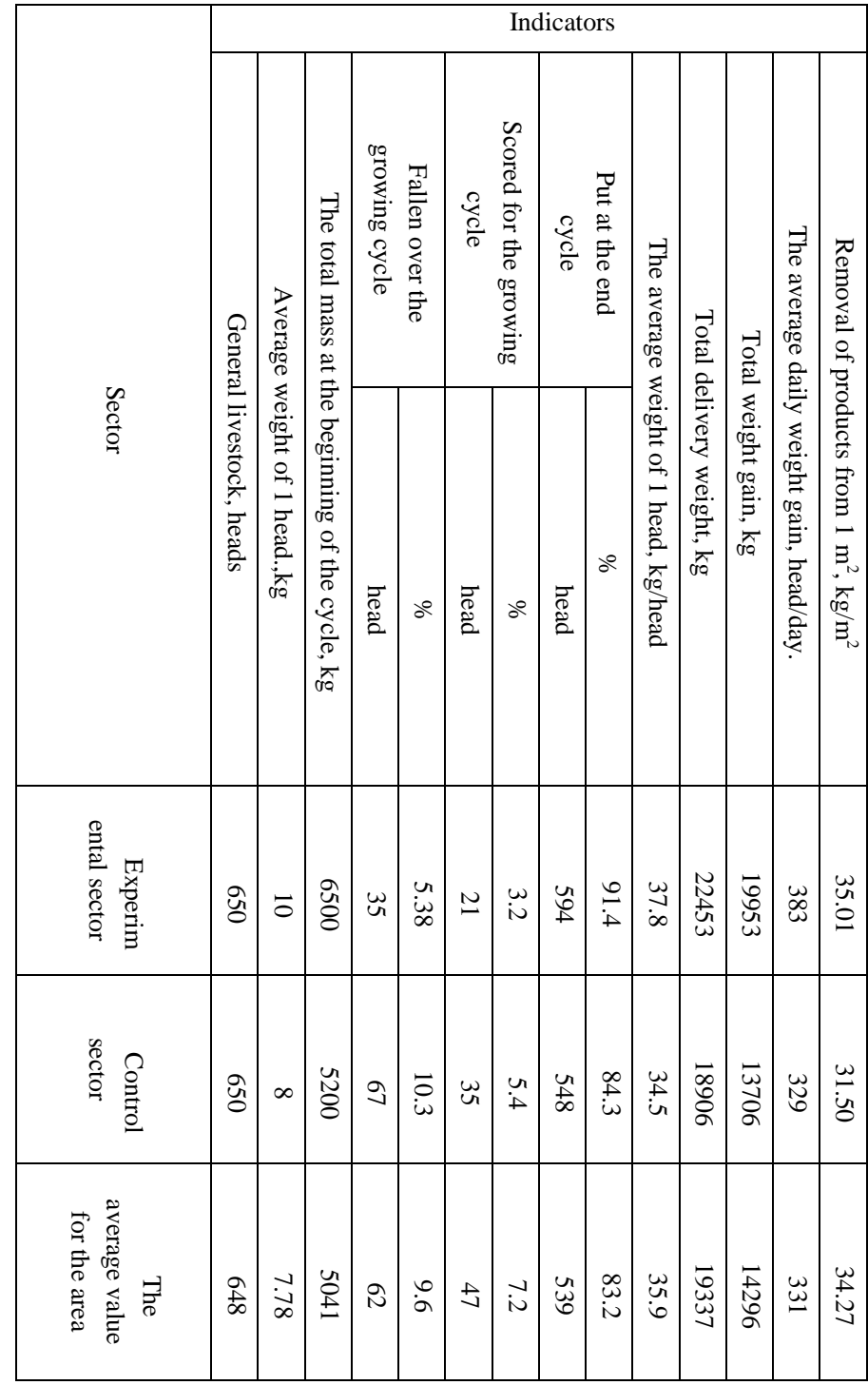

During the test of the electrostatic precipitator for control and experimental sectors, the authors were maintaining records of key production indicators (table 1). The results show that the electrofiltration of the air in the sector for 
maintenance of piglets weaned has a positive effect on their development and preservation.

The diagram is built according to the table (Fig. 4), which show that the mortality of piglets weaned in the experimental sector compared to the control is decreased by $52 \%$, the average daily weight gain has increased by $16.4 \%$, production output per square meter rose by $11 \%$, and the safety of piglets weaned has increased by $8.4 \%$.

In the pig`s farms "Consent" and "Kashtak", the production test for the system of cleaning recirculated air, based on wet electrostatic precipitator, was conducted in the area of fattening pigs (2-4 months).

Fig. 5 shows the dynamics of changes in daily weight gains and safety in this area. As can be seen, the average daily gain increased by $54 \mathrm{~g}$ per head, and the safety increased by nearly $4 \%$.

Thus, there is a clear beneficial effect of electrofiltration of recirculated indoor air for the fattening piglets and in the shop of piglets weaned.

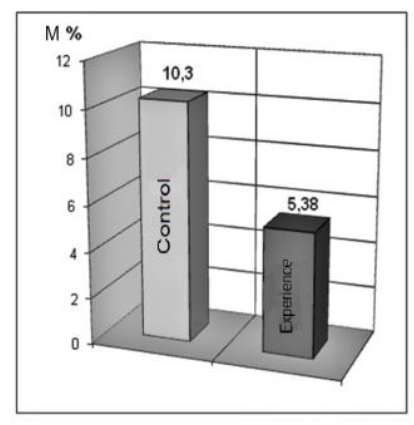

a)

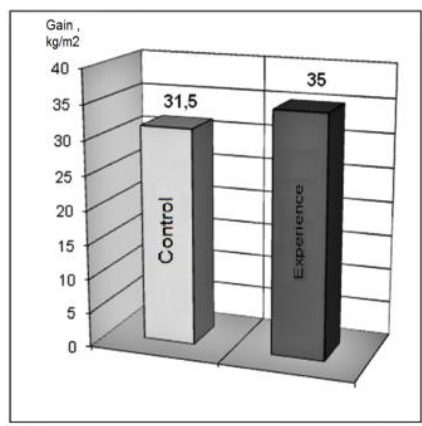

c)

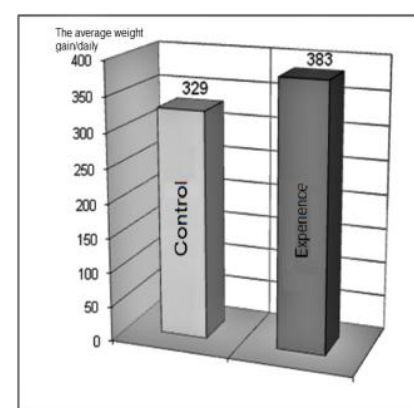

b)

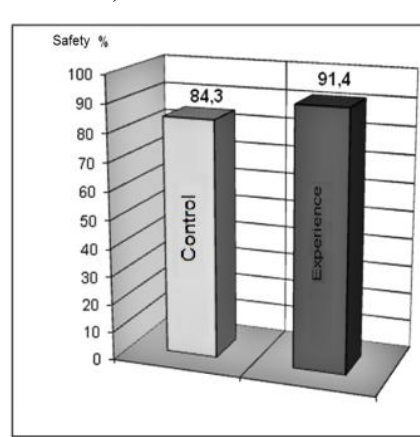

d)
Fig. 6. The influence of the wet electrostatic precipitator on the production indicators of the pig farm: (a) mortality; (b) average daily weight gain; (c) removal of products from $1 \mathrm{~m} 2$; (d) safety.

Thus, one can conclude that the system of partial recirculation of ventilation air, based on the wet single-zone electrostatic precipitator, allows one to reduce the power consumption of the livestock sector through recycling and retaining heat inside of the livestock facilities. In addition it allows one to improve production performance (survival and weight gain) with simultaneous reduction of the mortality rate of the animals due to the effective cleaning and disinfection of the air from harmful active components (dust particles, microorganisms and harmful gases).
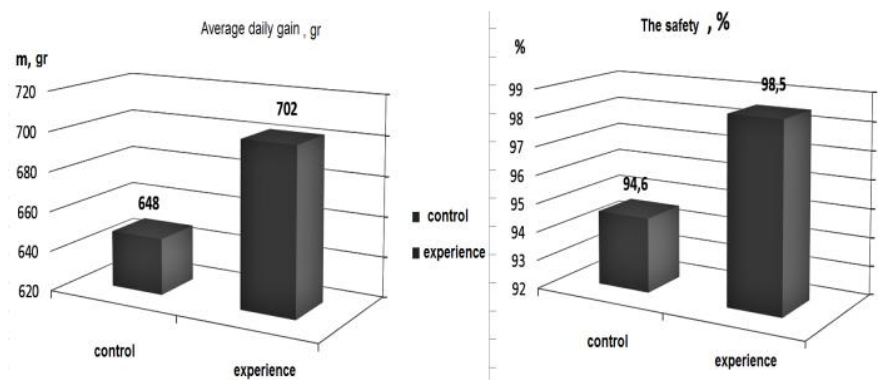

Fig. 7. The influence of the wet electrostatic precipitator on the average daily gain (a) of safety (\%) and (b) of the weight of the piglets for fattening (g)

To improve the efficiency of purification and decontamination of the ventilation air with partial recirculation of the air, based on wet electrostatic precipitators, primarily hydrogen sulfide (Fig. 3), and to increase the efficiency of purification from dust, germs and ammonia, a special twostage wet electrostatic precipitator (TSWEP) was developed $[6,7,8]$, consisting of two wet single-zone electrostatic precipitators. The first stage is designed to remove coarsely dispersed aerosol, microorganisms and ammonia; the second step is for cleaning from fine-dispersed aerosol and hydrogen sulfide, purification from microorganisms and ammonia. Design difference of wet electrostatic precipitators of the first and second stage is in the difference of the interelectrode distances, which allows one to increase the efficiency of cleaning dust and microorganisms and to increase the reliability of the entire system. The difference lies in the composition of the liquid for washing of the precipitation electrodes. In particular, in the first precipitator there is water and in the second - an aqueous solution of copper sulfate, which, according to the literature, absorbs hydrogen sulfide efficiently $[9,10]$. The general view of the two-stage wet electrostatic precipitator is given in Fig. 8
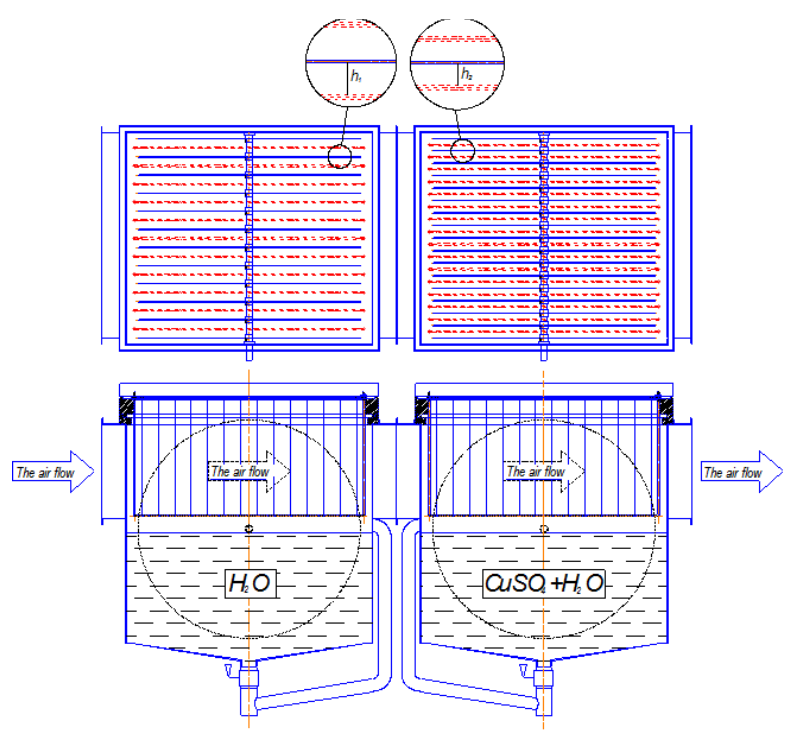

Fig. 8. General view of two-stage wet electrostatic precipitator 
One of the major technical indicators of the air cleaning devices is their efficiency. In general, the cleaning efficiency of the TSWEP could be calculated by the known formula:

$$
\eta=1-\left(1-\eta_{1}\right) \cdot\left(1-\eta_{2}\right)
$$

where $\eta 1, \eta 2$ - efficiency of cleaning the first and second stage TSWEP, respectively.

Using the formula of Deutsch to determine the efficiency of each of the stages, one can express the analytical expression for calculation of efficiency of the TSWEP for cleaning the air from dust and aerosol particles:

$$
\eta_{n}=1-\exp \left(-\frac{w_{1} l_{1} h_{2} u_{2}+w_{2} l_{2} h_{1} u_{1}}{h_{1} u_{1} h_{2} u_{2}}\right)
$$

On the basis of equation (4), let us obtain the expression for calculation of efficiency of the TSWEP for air purification from microorganisms:

$$
\eta_{K O E}=1-\left(1-\eta_{K O E 1}\right) \cdot\left(1-\eta_{K O E 2}\right)
$$

where $\eta_{K O E 1}=1-\left(1-\eta_{n 1}\right)^{0,66}$ - the efficiency of air purification from microorganisms in the first stage filter, $\eta_{K O E 2}=1-\left(1-\eta_{n 2}\right)^{0,66}$ efficiency for the second stage.

After substituting $\eta_{\text {КОЕ1 }}$ and $\eta_{\text {КОЕ } 2}$ in (7), one obtains an analytical expression for calculation of efficiency of air purification of the TSWEP from microorganisms:

$$
\eta_{K O E}=1-\left(1-\eta_{n 1}\right)^{0,66} \cdot\left(1-\eta_{n 2}\right)^{0,66}
$$

For the wet single-zone electrostatic precipitator, air cleaning efficiency of the i-th harmful gas is determined by expression (5).

In this case, one can write an analytical expression for calculation of efficiency of air purification of the TSWEP for the current harmful i-th gas:

$$
\eta_{i}=1-\left(1-\eta_{i 1}\right) \cdot\left(1-\eta_{i 2}\right)
$$
form:

Taking into account (5), expression (9) takes the following

$$
\begin{aligned}
& \eta_{i}=1-\left\{1-\left(1-\exp \left[-\frac{l_{1}}{u_{1}}\left(k_{O_{3}^{i 1}}^{i}+k_{w+1}^{i 1}\right)\right]\right)\right\} \cdot\left\{1-\left(1-\exp \left[-\frac{l_{2}}{u_{2}}\left(k_{O_{1}^{i 2}}^{i 2}+k_{w 2}^{i 2}\right)\right]\right\}\right\} \\
& =1-\exp \left[-\frac{l_{1}}{u_{1}}\left(k_{0_{3}^{i 1}}^{i 1}+k_{w+1}^{i 1}\right)-\frac{l_{2}}{u_{2}}\left(k_{O_{3}^{i 2}}^{i 2}+k_{w 2}^{i 2}\right)\right],
\end{aligned}
$$

where $\mathrm{k}_{{ }_{03}^{\prime}}^{\mathrm{i} 1}$ and $\mathrm{k}^{\mathrm{i} 2}{ }_{{ }_{03}^{\prime \prime}}$ the rate constant for the oxidation of i-th gas components of air and ozone, respectively, at the first and second stages; $\mathrm{k}^{\mathrm{i} 1}{ }_{\text {wf } 1} \mathrm{k}^{\mathrm{i} 2}{ }_{\text {wf } 2}-\mathrm{a}$ constant of speed of absorption of the i-th gas components of air washer fluid, respectively, in the first and second stages.

Thus, the feasibility and efficiency of the use of wet electrostatic precipitators in the system is justified and proven as a highly effective way of cleaning and disinfecting the ventilation air in livestock buildings. The proposed two-stage wet electrostatic precipitator with high efficiency indicators after comprehensive laboratory and industrial experiments could be recommended as an apparatus for cleaning and disinfection of ventilation of the internal air with increased requirements for the quality of the air environment.

\section{References}

[1] A.A. Dmitriyev, A.G. Vozmilov, L.N. Andreev, V.V. Yurkin, "Cleaning of ventilation air of pig farms," Pig Breeding, vol. 2, pp. 19-20, March 2015 .

[2] A.G. Vozmilov, M.V. Vlasov, "Exhaust air in industrial poultry farming," AIC of Russia, vol. 56, pp. 29-31, June 2010.

[3] S.I. Ivanov and G.N. Samarin, "Energy efficient microclimate formation," Rural mechanic, vol. 1(47), pp. 28-29, March 2013.

[4] A.G. Vozmilov, V.B. Fain, L.N. Andreev, A.A. Dmitriyev and V.V. Yurkin, "Analysis of air purification systems in livestock and poultry farms," Electrotechnical and information complexes and systems, vol. 4, pp. 45-51, December 2014.

[5] A.A. Dmitriyev, A.G. Vozmilov, L.N. Andreev and B.V. Zherebtsov, "Working full methods of calculating efficiency of air filtrations against dust, microorganisms and harmful gases with the two-stage wet electrostatic filter," Electrotechnical and information complexes and systems, vol. 4, pp. 60-65, December 2013.

[6] A.A. Dmitriyev, A.G. Vozmilov, L.N. Andreev and B.V. Zherebtsov, "About the main tasks to be solved in the design of wet electrostatic precipitators," Electrotechnical and information complexes and systems, vol. 1, pp. 24-28, March 2014

[7] N.I. Smolin, L.N. Andreev and V.V. Yurkin, "Investigation of operational characteristics of two-stage wet electrostatic precipitator in laboratory conditions," Vestnik Krasnoyarsk state agrarian University, vol. 8, pp. 115-122, August 2016.

[8] A.G. Vozmilov and L.N. Andreev, "Energy efficient technologies microclimate in livestock," Veterinary, vol. 1, pp. 12-17, January 2016.

[9] L.N. Andreev, "Improving the environmental sustainability of industrial livestock," Vestnik Krasnoyarsk state agrarian University, vol. 11, pp. 77-84, November 2015.

[10] A.A. Dmitriyev and V.P. Frayshteter, "Improving energy efficiency of building heating and ventilation systems by use of two-stage electrostatic precipitator," Oil industry, vol. 6, pp. 122-123, June 2014. 